\title{
HEMIMASTICATORY SPASM TREATED WITH BOTULINUM TOXIN
}

\section{Case report}

\author{
Hélio A. G. Teive', Élcio J. Piovesan'², Francisco M.B. Germiniani ${ }^{3}$, \\ Carlos Henrique A. Camargo ${ }^{3}$, Daniel Sá ${ }^{3}$, Rosana H. Scola ${ }^{4}$, Lineu C. Werneck ${ }^{5}$
}

\begin{abstract}
We describe a female patient with hemimasticatory spasm, a rare movement disorder due to dysfunction of the motor trigeminal nerve of unknown origin. This patient had an excellent response to botulinum toxin therapy.
\end{abstract}

KEY WORDS: hemimasticatory spasm, paroxysmal spasms, botulinum toxin.

\begin{abstract}
Espasmo hemimastigatório tratado com toxina botulínica: relato de caso
RESUMO - Relatamos o caso de paciente feminina com espasmo hemimastigatório, distúrbio do movimento raro decorrente de disfunção da porção motora do nervo trigeminal, de etiologia desconhecida. A paciente teve excelente resposta clínica ao tratamento com toxina botulínica.
\end{abstract}

PALAVRAS-CHAVE: espasmo hemimastigatório, espasmos paroxísticos, toxina botulínica.

Hemimasticatory spasm (HMS) represents a rare movement disorder due to a dysfunction of the motor trigeminal nerve of unknown origin. It is frequently misdiagnosed as hemifacial spasm, which is a disorder due to dysfunction of the facial nerve ${ }^{1-3}$. The most striking features of HMS are the excruciating pain that accompanies the spasm itself and the fact that initially masticatory movements act as a trigger for the spasm ${ }^{1-3}$. There are many options for the treatment of HMS, raging from medical to surgical approaches. A milestone in the treatment of HMS was botulinum toxin, which has become the treatment of choice due to its excellent results. We report a HMS case.

\section{CASE}

A 44 years old female patient came to our service complaining of facial spasms and severe pain compromising the right temporal region and the right side of the face and lasting 1 up to 2 minutes. The symptoms were triggered by masticatory movements at first, but more recently they needed no triggering factor and appeared spontaneously. She also complained of difficulty in talking and swallowing when she had the spasms.

Neurological examination was normal except for intense contraction of the masseter and temporal muscles on the right with severe facial pain when the patient had the spasms. Routine laboratory tests (WBC, biochemistry, VDRL, ERS) and ceruloplasmine were all normal.

The patient also had a previous history of irregular menstrual cycles and even amenorrhea for more than one year. Endocrinological investigation disclosed increased prolactin levels (61.34; normal: 1.39 - 24.20) and normal thyroid tests: TSH 1.458 (normal range: 0.490 - 4.670), T3 86.12 (normal range: 45 - 137) and T4 7.64 (normal range: 4.5 - 12). Cranial computed tomography (CT) and a magnetic resonance imaging (MRI) were normal. The patient was treated with several drugs such as carbamazepine, clonazepam and gabapentin with no improvement whatsoever.

An electrophysiologic study (electromyography of the right masseter and temporal muscles) was performed, which disclosed bursts of motor unit potentials, with duration of 40 seconds and irregular frequency, during hemimasticatory spasm. Electromyography-guided injection of 100 units

Study performed at the Movement Disorders Unit, Service of Neurology, Hospital de Clínicas, Universidade Federal do Paraná (UFPR), Curitiba PR, Brazil: ${ }^{1}$ Assistant Professor of Neurology; ${ }^{2}$ Neurologist; ${ }^{3}$ Resident in Neurology; ${ }^{4}$ Adjunct Professor of Internal Medicine; ${ }^{5}$ Full Professor of Neurology Head of the Service of Neurology. This paper was presented as a poster at the Sixth International Congress of Parkinson's Disease and Movement Disorders in Barcelona, Spain, 11-15 th June, 2000.

Received 8 July 2001, received in final form 12 November 2001. Accepted 21 November 2001.

Dr. Hélio A. G. Teive - Rua General Carneiro 1103/102 - 80.060-150 Curitiba - PR - Brasil. E-mail: hagteive@mps.com.br 
of botulinum toxin (Botox, Allergan) in both the right masseter and right temporal muscles was then performed, leading to a remarkable improvement of symptom. The duration of effect was three months, when a new injection of botulinum toxin had the same result.

\section{DISCUSSION}

HMS is a rare movement disorder of unknown origin $^{1,2}$ that affects more women in the third and fourth decades. It's probably due to a disorder of the trigeminal nerve, similar to the one found in ordinary hemifacial-spasm. Entrapment of the motor branches of the trigeminal nerve in the infratemporal fossa ${ }^{2,3}$ leads to paroxysmal involuntary contraction of the jaw muscles with involuntary jaw closing $^{1}$. Other authors believe that a vascular compression near the brainstem is the cause of $\mathrm{HMS}^{2}$. To some extend, lack of inhibition of masseter muscle contraction may play a role in the etiology of HMS.

The muscles commonly affected are the masseter, temporalis and medial pterigoid ${ }^{1}$. Brief, paroxysmal spasms are separated in time by variable symptomsfree intervals and are not linked to specific tasks ${ }^{1}$. The aforementioned muscles can be hypertrophied in HMS, as opposed to the facial muscles affected in hemifacial spasm, which do not get hypertrophied ${ }^{1}$. Such hypertrophy, as well as dislocation of the jaw, can be seen by CT or MRI of the face ${ }^{2}$. There can also be asymmetrical jaw jerks². Muscle biopsy is usually normal, sometimes with signs of skin atrophy.

Another clinically distinct feature of HMS is that it may be painful, while hemifacial spasm tends to be not related to pain of any kind. HMS can also be associated with hemifacial atrophy ${ }^{1-3}$ in some cases, but this association is not obligatory.

Electrophysiologic study disclosesan irregular bursts of motor unit potentials, similar to the findings of ordinary hemifacial spasm and absent masseter inhibitory reflex ${ }^{1,2}$. This electrographic pattem suggests that there is an ectopic excitation of the motor root of the trigeminal nerve, rather than a central origin ${ }^{1}$.

The electrophysiologic findings are characteristic and help in the differential diagnosis with other conditions, such as unilateral dystonia of the jaw with jaw closure, temporomandibular joint syndrome, paroxysmal events in multiple sclerosis and tetany ${ }^{4,5}$. To that effect, EMG shows unilateral discharges and focal hypertrophy ${ }^{1}$.
Treatment options for HMS include the use of oral drugs, surgical treatment and injection of botulinum toxin ${ }^{1,3,5}$. The latter seems to be the treatment option with the best outcome. The drugs that have been used in the treatment of HMS are phenytoin, carbamazepine, clonazepam, diazepam, dantrolene, baclofen, valproate, haloperidol, amitriptyline, cyclobenzaprine and trihexyphenidril, all of them with poor clinical improvement, except maybe for carbamazepine and phenytoin ${ }^{1}$.

Botulinum toxin is now available for a wide spectrum of conditions characterized by muscle over-contraction, including dystonia, hemifacial spasm and spasticity among other indications ${ }^{6}$. Remarkable results have occurred in the treatment of focal dystonia and particularly hemifacial spasm, an entity very similar to $\mathrm{HMS}^{6}$. Auger et al. published a clinical and electrophysiologic observations on 3 cases of hemimasticatory spasm, and one of them responded favorably to botulinum toxin injections ${ }^{1}$. Ebersbach et al. reported two cases of hemimasticatory spasm in hemifacial atrophy; injections of botulinum toxin type $A$ into the masticatory muscles proved to be a successful treatment in both patients ${ }^{3}$. Kim et al. reported a case of hemimasticatory spasm associated with localized scleroderma and facial hemiatrophy; the authors described excellent results after the use of botulinum toxin type A injections ${ }^{7}$.

HMS is a highly debilitating movement disorder. It's probably due to a dysfunction of the trigeminal nerve, similar to the one found in ordinary hemifacial-spasm. Our patient showed an excellent response to botulinum toxin therapy.

\section{REFERENCES}

1. Auger RG, Litchy WJ, Cascino TL, Ahlskog JE. Hemimasticatory spasm: clinical and electrophysiologic observations. Neurology 1992;42:22632266.

2. Cruccu G, Inghilleri M, Berardelli A, et al. Pathophysiology of hemimasticatory spasm. J Neurol Neurosurg Psychiatry 1994;57:43-50.

3. Ebersbach G, Kabus C, Schelosky L, Terstegge L, Poewe W. Hemimasticatory spasm in hemifacial atrophy: diagnostic and therapeutic aspects in two patients. Mov Disord 1995;10:504-507.

4. Thompson PD, Obeso JA, Delgado G, Gallego J, Marsden CD. Focal dystonia of the jaw and the differential diagnosis of unilateral jaw and masticatory spasm. J Neurol Neurosurg Psychiatry 1986;49:651-666.

5. Lagueny A, Deliac MM, Julien J, Demotes Mainard J, Ferrer X. Jaw closing spasm - a form of focal dystonia? An electrophysiological study. J Neurol Neurosurg Psychiatry 1989;52:652-655.

6. Moore AP. General and clinical aspects of treatment with botulinum toxin. In Moore P. Handbook of botulinum toxin. Oxford, UK: Blackwell Science 1995:28-53.

7. Kim HJ, Jeon BS, Lee KW. Hemimasticatory spasm associated with localized scleroderma and facial hemiatrophy. Arch Neurol 2000;57:576580 